CUBO A Mathematical Journal

Vol.17, $N^{\underline{O}}$ 01, (11-27). March 2015

\title{
Periodic BVP for a class of nonlinear differential equation with a deviated argument and integrable impulses
}

\author{
Alka Chadha and DwiJendra N Pandey \\ Department of Mathematics, \\ Indian Institute of Technology Roorkee, \\ Roorkee-247667 \\ alkachaddha03@gmail.com, dwij.iitk@gmail.com
}

\begin{abstract}
This paper deals with periodic BVP for integer/fractional order differential equations with a deviated argument and integrable impulses in arbitrary Banach space $\mathbf{X}$ for which the impulses are not instantaneous. By utilizing fixed point theorems, we firstly establish the existence and uniqueness of the mild solution for the integer order differential system and secondly obtain the existence results for the mild solution to the fractional order differential system. Also at the end, we present some examples to show the effectiveness of the discussed abstract theory.
\end{abstract}

\section{RESUMEN}

Este artículo estudia las ecuaciones diferenciales de orden entero/fraccional con condiciones de frontera periódicas con un argumento desviado e impulsos integrables en espacios de Banach arbitrarios $\mathrm{X}$ donde los pulsos no son instantáneos. Utilizando teoremas de punto fijo, establecemos la existencia y unicidad de soluciones temperadas para los sistemas diferenciales de orden entero, y luego obtenemos resultados de existencia para soluciones temperadas del sistema diferencial de orden fraccional. Además, presentamos un ejemplo para mostrar la efectividad de la teoría abstracta discutida.

Keywords and Phrases: Deviating arguments, Fixed point theorem, Impulsive differential equation, Periodic BVP, Fractional calculus.

2010 AMS Mathematics Subject Classification: 34G20, 34K37, 34K45, 35R12, 45J05. 


\section{Introduction:}

In a few decades, impulsive differential equations have received much attention of researchers mainly due to its demonstrated applications in widespread fields of science and engineering. Impulsive differential equations have played an important role in real world problems for describing a process which is characterized by the development of a sudden change in system's state. Such processes are investigated in various fields such as biology, physics, control theory, population dynamics, medicine and many others. Impulsive differential equations are an appropriate model to hereditary phenomena for which a delay argument arises in modelling equations. For more details on impulsive differential equation, we refer to the monographs [1],[2] and papers [3]-[12] and references given therein.

A differential equation with boundary conditions arise in many areas of applied sciences, for example, chemical engineering, blood flow problems, thermoelasticity, population models, underground water flow and many others. For more details on differential equation with integral boundary conditions, we refer to $[10,17,18,19,23,27]$ and references given therein. On the other hand, fractional calculus have many applications in various areas of sciences and engineering for example, fluid dynamics, like fractal theory, diffusion in porous media and fractional biological neurons, traffic flow, polymer rheology. The fractional differential equation is an important tool to describe nonlinear oscillation of earthquake. For more study on fractional calclus, we refer to books [13]-[16].

In this work, we consider the periodic boundary value problems for integer order nonlinear differential equations in a Banach space $\mathbf{X}$ of the form with non-instantaneous integrable impulses

$$
\begin{aligned}
u^{\prime}(t) & =f(t, u(t), u([h(u(t), t)])), t \in\left(s_{m}, t_{m+1}\right], m=0,1,2, \cdots, \delta, \\
u(t) & =\int_{t_{m}}^{t} G_{m}(s, u(s)) d s, t \in\left(t_{m}, s_{m}\right], m=1,2, \cdots, \delta, \delta \in \mathbb{N} \\
u(0) & =u(T) .
\end{aligned}
$$

Next, we consider the periodic boundary value problems for nonlinear fractional differential equations in a Banach space $X$ of the form with non-instantaneous integrable impulses

$$
\begin{aligned}
{ }^{c} D_{0, t}^{q} u(t) & =I_{t}^{2-q} f(t, u(t), u([h(u(t), t)])), \quad t \in\left(s_{m}, t_{m+1}\right], \quad 0<q<1, \\
u(t) & =\int_{t_{m}}^{t} G_{m}(s, u(s)) d s, t \in\left(t_{m}, s_{m}\right], \quad m=0,1,2, \cdots, \delta, \delta \in \mathbb{N}, \\
u(0) & =u(T),
\end{aligned}
$$

where $0<\mathrm{T}<\infty,{ }^{\mathrm{c}} \mathrm{D}_{0, \mathrm{t}}^{\mathrm{q}}$ represents the Caputo fractional derivative of the order $\mathrm{q}$ with lower limit $0,0=t_{0}=s_{0}<t_{1} \leq s_{1} \leq t_{2}<\cdots<t_{\delta} \leq s_{\delta} \leq t_{\delta+1}=T$ are fixed numbers, $G_{m}:\left(t_{m}, s_{m}\right] \times X \rightarrow X, m=1, \cdots, \delta$. The nonlinear $X$-valued functions $f$ and $h$ are appropriate functions and satisfy some suitable conditions to be stated later. In this system of equations 
(1.1)-(1.3) and (1.4)-(1.6), the impulses begin all of a sudden at the points $t_{i}$ and continue their proceeding on a finite interval $\left[t_{i}, s_{i}\right]$. According to the authors in [4]-[5], there are many different inspirations for consideration of the problem (1.1)-(1.3) and (1.4)-(1.6). The hemodynamical equilibrium of a person is an example of such systems. One can prescribe some intravenous drugs (insulin) in the case of a decompensation (for example, low or high level of glucose). Since the introduction of the drugs in the bloodstream and the consequent absorption of the body are successive and continuous processes, we can describe this situation as an impulsive action which start suddenly and stays active on a finite time interval.

The organization of the paper is as follows: In section 2, we give some basic definitions, assumptions, lemmas and theorems as preliminaries which will be used for proving our main results. In section 3, we prove the existence of a mild solution to the problem (1.1)-(1.3) and problem (1.4)-(1.6). Some examples are also presented at the end of the paper.

\section{Preliminaries and Assumptions}

In this section, we discuss some basic definitions, preliminaries, theorem and lemmas which will be used for proving the required result.

Let $(X,\|\cdot\|)$ be a Banach space. Let $C(J ; X)$, where $J=[0, T]$ denotes the space of all continuous $X$-valued functions on interval $J$ which is a Banach space with the norm $\|u\|_{C}=\sup _{t \in J}\|\mathfrak{u}(t)\|$. The space of all Bochner integrable functions $u:(0, T) \rightarrow X$ represented by $L^{1}((0, T) ; X)$, is a Banach space with norm $\|u\|_{1}=\int_{0}^{T}\|u(t)\| d t$. The $B_{r}(x, X)$ denotes the closed ball with center at $x$ and radius $r$ in $X$.

To study the impulsive differential equation, we introduce the following space

$$
\begin{aligned}
\mathcal{P C}([0, T] ; X)= & \left\{\mathfrak{u}:[0, T] \rightarrow X ; u \in C\left(\left(t_{j}, t_{j+1}\right] ; X\right), \quad j=0,1, \cdots, m\right. \text {, and } \\
& \left.\exists \mathfrak{u}\left(t_{j}^{+}\right) \text {and } \mathfrak{u}\left(t_{j}^{-}\right), j=1, \cdots, m \text { exist with } \mathfrak{u}\left(t_{j}^{-}\right)=\mathfrak{u}\left(t_{j}\right)\right\} .
\end{aligned}
$$

It is clear that $\mathcal{P C}([0, \mathrm{~T}] ; \mathrm{X})$ is a Banach space with the norm

$$
\|\mathrm{u}\|_{\mathcal{P C}}=\max _{\mathrm{t} \in[0, \mathrm{~T}]}\|\mathrm{u}(\mathrm{t})\| .
$$

For a function $u \in \mathcal{P C}([0, T] ; X)$ and $j \in\{0,1, \cdots, m\}$, we define the function $\widetilde{u_{j}} \in \mathcal{C}\left(\left[t_{j}, t_{j+1}\right] ; X\right)$ such that

$$
\widetilde{u_{j}}(t)= \begin{cases}u(t), & \text { for } t \in\left(t_{j}, t_{j+1}\right], \\ u\left(t_{j}^{+}\right), & \text {for } t=t_{j} .\end{cases}
$$

For $\mathrm{B} \subset \mathcal{P C}([0, T] ; X)$ and $j \in\{0,1, \cdots, m\}$, we have $\widetilde{B_{j}}=\left\{\widetilde{u_{j}}: u \in B\right\}$ and we have following Accoli-Arzelà type criteria. 
Lemma 2.1. [4]. A set $B \subset \mathcal{P C}([0, T] ; X)$ is relatively compact in $\mathcal{P C}([0, T] ; X)$ if and only if each set $\widetilde{B_{j}}(j=1,2, \cdots, m)$ is relatively compact in $C\left(\left[t_{j}, t_{j+1}\right], X\right)(j=0,1, \cdots, m)$.

Now, we recall some basic definition.

Definition 2.1. The Riemann-Liouville fractional integral of $f$ with order $q$ defined by

$$
I_{0, t}^{q} f(t)=\frac{1}{\Gamma(q)} \int_{0}^{t}(t-s)^{q-1} f(s) d s .
$$

Definition 2.2. The fractional derivative of function $f:[0, \infty) \rightarrow \mathbb{R}$ in the Riemann-Liouville sense with order $q$ is defined by

$$
D_{0, t}^{q} f(t)=\frac{d^{n}}{d t^{n}} \frac{1}{\Gamma(n-q)} \int_{0}^{t}(t-s)^{n-q-1} f(s) d s, \quad t>0, \quad n-1<q<n .
$$

Definition 2.3. The fractional derivative of function $f:[0, \infty) \rightarrow \mathbb{R}$ in the Caputo sense of order $\mathrm{q}$ is defined by

$$
{ }^{c} D_{0, t}^{q} f(t)=\frac{1}{\Gamma(n-q)} \int_{0}^{t}(t-s)^{n-q-1} f^{n}(s) d s
$$

for $\mathrm{n}-1<\mathrm{q}<\mathrm{n}, \mathrm{n} \in \mathbb{N}, \mathrm{t}>0$, with the following property:

$$
{ }^{c} D_{0, t}^{q}\left(I_{0, t}^{q} f(t)\right)=f(t)-\sum_{k=1}^{n-1} \frac{t^{k}}{k !} f^{k}(0) .
$$

Before expressing and demonstrating the required main result, we present the following definition of mild solution to the system (1.1)-(1.3) and (1.4)-(1.6).

Lemma 2.2. For given continuous function $f:[0, T] \rightarrow X$ and $G_{m} \in C\left(\left[t_{m}, s_{m}\right], X\right)$, a function $u \in \mathcal{P C}([0, T] ; X)$ is a mild solution for the impulsive periodic boundary value problem

$$
\begin{aligned}
u^{\prime}(t) & =f(t), t \in\left(s_{m}, t_{m+1}\right], m=0,1,2, \cdots, \delta, \delta \in \mathbb{N} \\
u(t) & =\int_{t_{m}}^{t} G_{m}(s) d s, t \in\left(t_{m}, s_{m}\right], m=1,2, \cdots, \delta, \\
u(0) & =u(T),
\end{aligned}
$$

if and only if $\mathfrak{u}(\cdot)$ satisfies the following

$$
u(t)=\left\{\begin{array}{lr}
\int_{t_{\delta}}^{s_{\delta}} G_{\delta}(s) d s+\int_{s_{\delta}}^{T} f(s) d s+\int_{0}^{t} f(s) d s, & t \in\left[0, t_{1}\right], \\
\int_{t_{m}}^{s_{m}} G_{m}(s) d s+\int_{s_{m}}^{t} f(s) d s, & t \in\left(s_{m}, t_{m+1}\right], \\
\int_{t_{m}}^{t} G_{m}(s) d s, & t \in\left(t_{m}, s_{m}\right],
\end{array}\right.
$$

for each $m=1, \cdots, \delta$. 
Lemma 2.3. For the continuous function $f:[0, T] \rightarrow X$ and $G_{m} \in C\left(\left[t_{m}, s_{m}\right], X\right)$, a function $u \in \mathcal{P C}([0, T] ; X)$ is said to be a mild solution for the system

$$
\begin{aligned}
{ }^{c} D_{0, t}^{q} u(t) & =I_{t}^{2-q} f(t), \quad t \in\left(s_{m}, t_{m+1}\right], \quad 0<q<1, \\
u(t) & =\int_{t_{m}}^{t} G_{m}(s) d s, t \in\left(t_{m}, s_{m}\right], \quad m=0,1,2, \cdots, \delta, \delta \in \mathbb{N}, \\
u(0) & =u(T),
\end{aligned}
$$

if and only if $u(0)=u(T), u(t)=\int_{t_{m}}^{t} G_{m}(t), \forall t \in\left(t_{m}, s_{m}\right], m=1, \cdots, \delta$ and $u(\cdot)$ satisfies the following integral equations

$$
u(t)=\left\{\begin{array}{l}
\int_{t_{\delta}}^{s_{\delta}} G_{\delta}(s) d s-\int_{0}^{s_{\delta}}\left(s_{\delta}-s\right) f(s) d s+\int_{0}^{T}(T-s) f(s) d s \\
+\int_{0}^{t}(t-s) f(s) d s, \quad t \in\left[0, t_{1}\right], \\
\int_{t_{m}}^{s_{m}} G_{m}(s) d s-\int_{0}^{s_{m}}\left(s_{m}-s\right) f(s) d s+\int_{0}^{t}(t-s) f(s) d s, t \in\left(s_{m}, t_{m+1}\right],
\end{array}\right.
$$

for each $m=1, \cdots, \delta$.

Further, we list the following assumption which will be used to establish the main result.

Assumptions on $f, h$ and $G_{m},(m=1, \cdots, \delta)$ :

(A1) The function $f:[0, T] \times X \times X \rightarrow X$ is continuous and there exist a positive constant $L_{f}$ and $0<\gamma_{1} \leq 1$ such that

$$
\left\|f\left(t_{1}, u_{1}, v_{1}\right)-f\left(t_{2}, u_{2}, v_{2}\right)\right\| \leq L_{f}\left[\left|t_{1}-t_{2}\right|^{\gamma_{1}}+\left\|u_{1}-u_{2}\right\| x+\left\|v_{1}-v_{2}\right\|_{x}\right],
$$

for all $\left(t_{j}, u_{j}, v_{j}\right) \in[0, T] \times X \times X, j=1,2$.

(A2) $h: X \times[0, T] \rightarrow[0, T]$ is continuous function and there exist positive constants $L_{h}$ and $0<\gamma_{2} \leq 1$ such that

$$
\left|h\left(u_{1}, t_{1}\right)-h\left(u_{2}, t_{2}\right)\right| \leq L_{h}\left[\left\|u_{1}-u_{2}\right\|_{x}+\left|t_{1}-t_{2}\right|^{\gamma_{2}}\right],
$$

for each $\left(u_{j}, t_{j}\right) \in X \times[0, T]$, for $j=1,2$.

(A3) $G_{m}:[0, T] \times X \rightarrow X, m=1,2, \cdots, \delta$, are continuous functions and there exist constants $\mathrm{L}_{\mathrm{G}_{\mathrm{m}}}>0$ such that

$$
\begin{aligned}
\left\|G_{m}(t, x)-G_{m}(t, y)\right\| & \leq L_{G_{m}}\|x-y\|, \\
\left\|G_{m}(t, u(t))\right\| & \leq \mathcal{K}_{m},
\end{aligned}
$$

for all $(t, x),(s, y) \in[0, T] \times X, u \in X$ and $\mathcal{K}_{m}>0, m=1, \cdots, \delta$ are constants. 


\section{Existence Result}

In this section, we establish the existence of a mild solutions for the systems (1.1)-(1.3) and (1.4)(1.6) by using fixed point theorems.

Let

$$
\begin{aligned}
Y_{0}=\mathcal{P C}(J ; X)= & \left\{y \in P C(J ; X): y \in C\left(\left(t_{m}, t_{m+1}\right], X\right), m=0,1, \cdots, \delta\right. \\
& \text { and } \left.y\left(t_{m}^{-}\right)=y\left(t_{m}\right), y\left(t_{m}^{+}\right) \text {exist }\right\} .
\end{aligned}
$$

and

$$
Y_{1}=\left\{y \in Y_{0}:\|y(t)-y(s)\| \leq \mathcal{L}|t-s|, \forall t \in\left[t_{m}, t_{m+1}\right], m=0,1, \cdots, \delta\right\} .
$$

Where $\mathcal{L}$ is an appropriate positive constant to be defined later.

\subsection{Integer Order case}

Theorem 3.1. We assume that assumptions $(A 1)-(A 3)$ are satisfied. If

$$
\begin{aligned}
\Theta= & \sup \left\{\max _{\mathrm{m}=1, \cdots, \delta}\left[\mathrm{L}_{\mathrm{G}_{\mathrm{m}}}\left(\mathrm{s}_{\mathrm{m}}-\mathrm{t}_{\mathrm{m}}\right)+\mathrm{L}_{\mathrm{f}}\left(1+\mathrm{L}_{\mathrm{h}} \mathcal{L}\right)\left(\mathrm{t}_{\mathrm{m}+1}-\mathrm{s}_{\mathrm{m}}\right)\right],\right. \\
& \left.\mathrm{L}_{\mathrm{G}_{\delta}}\left(\mathrm{s}_{\delta}-\mathrm{t}_{\delta}\right)+\mathrm{L}_{\mathrm{f}}\left(1+\mathrm{L}_{\mathrm{h}} \mathcal{L}\right)\left(\mathrm{T}-\mathrm{s}_{\delta}+\mathrm{t}_{1}\right)\right\}<1 .
\end{aligned}
$$

Then, the system (1.1)-(1.3) has a unique mild solution on the interval J.

Proof. In order to transform the system (1.1)-(1.3) into a fixed point problem, we consider the map $\mathrm{Q}: \mathcal{S} \rightarrow \mathcal{S}$ defined by

$$
Q u(t)=\left\{\begin{array}{l}
\int_{t_{m}}^{t} G_{m}(s, u(s)) d s, \quad t \in\left(t_{m}, s_{m}\right], m=1, \cdots, \delta, \\
\int_{t_{\delta}}^{s_{\delta}} G_{\delta}(s, u(s)) d s+\int_{s \delta}^{T} f(s, u(s), u([h(u(s), s)])) d s \\
+\int_{0}^{t} f(s, u(s), u([h(u(s), s)])) d s, \quad t \in\left[0, t_{1}\right], \\
\int_{t_{\delta}}^{s_{\delta}} G_{m}(s, u(s)) d s+\int_{s_{m}}^{t} f(s, u(s), u([h(u(s), s)])) d s, t \in\left(s_{m}, t_{m+1}\right]
\end{array}\right.
$$

where $\mathcal{S}=\left\{\mathfrak{u} \in \mathrm{Y}_{0} \cap \mathrm{Y}_{1}:\|\mathrm{u}\|_{\mathcal{P C}} \leq \mathrm{R}\right\}$. Clearly, $\mathcal{S}$ is a closed and bounded subset of $\mathrm{Y}_{1}$ and complete metric space. It is not difficult to show that $Q u \in Y_{0}$. Now, it remains to show that $Q u \in Y_{1}$. For $u \in \mathcal{S}$ and $\tau_{2}, \tau_{1} \in\left[0, t_{1}\right]$ with $\tau_{1}<\tau_{2}$,

$$
\begin{aligned}
\left\|\mathrm{Qu}\left(\tau_{2}\right)-\mathrm{Qu}\left(\tau_{1}\right)\right\| & \leq \int_{\tau_{1}}^{\tau_{2}}\|f(s, u(s), u([h(u(s), s)]))\| \mathrm{d} s \\
& \leq \mathrm{H}\left|\tau_{2}-\tau_{1}\right| .
\end{aligned}
$$

where $H=\sup _{t \in[0, T]}\|f(t, u(t), u([h(u(t), t)]))\|$. Similarly, $\tau_{2}, \tau_{1} \in\left(t_{m}, s_{m}\right], m=1, \cdots, \delta$

$$
\begin{aligned}
\left\|\mathrm{Qu}\left(\tau_{2}\right)-\mathrm{Qu}\left(\tau_{1}\right)\right\| & \leq\left\|\int_{\mathfrak{t}_{\mathrm{m}}}^{\tau_{2}} \mathrm{G}_{\mathrm{m}}(\mathrm{s}, \mathrm{u}(\mathrm{s})) \mathrm{ds}-\int_{\mathrm{t}_{\mathrm{m}}}^{\tau_{1}} \mathrm{G}_{\mathrm{m}}(\mathrm{s}, \mathrm{u}(\mathrm{s})) \mathrm{d}\right\| \\
& \leq \mathcal{K}_{\mathrm{m}}\left|\tau_{2}-\tau_{1}\right|
\end{aligned}
$$


and for $\tau_{2}, \tau_{1} \in\left(s_{m}, t_{m+1}\right], m=1, \cdots, \delta$

$$
\left\|\mathrm{Qu}\left(\tau_{2}\right)-\mathrm{Qu}\left(\tau_{1}\right)\right\| \leq \mathrm{H}\left|\tau_{2}-\tau_{1}\right| .
$$

Therefore, we conclude that $\mathrm{Qu} \in \mathrm{Y}_{1}$ with suitable constant

$$
\mathcal{L}=\min \left\{\max _{m=1, \cdots, \delta} \mathcal{K}_{m}, \mathrm{H}\right\} .
$$

Now, we show that $\mathrm{Q}(\mathcal{S}) \subseteq \mathcal{S}$. For $\mathrm{t} \in\left[0, \mathrm{t}_{1}\right]$ and $\boldsymbol{u} \in \mathcal{S}$, we get

$$
\begin{aligned}
\|Q u(t)\| \leq & \left\|\int_{t_{\delta}}^{s_{\delta}} G_{\delta}(s, u(s)) d s\right\|+\int_{s_{\delta}}^{T}\|f(s, u(s), u([h(u(s), s)]))\| d s \\
& +\int_{0}^{t}\|f(s, u(s), u([h(u(s), s)]))\| d s, \\
\leq & \mathcal{K}_{\delta}\left(s_{\delta}-t_{\delta}\right)+H\left(T-s_{\delta}+t_{1}\right) \leq \mathcal{K}_{\delta} T+H T .
\end{aligned}
$$

For $t \in\left[s_{m}, t_{m+1}\right], m=1, \cdots, \delta$,

$$
\|\mathrm{Qu}(\mathrm{t})\| \leq \mathcal{K}_{\mathrm{m}}\left(\mathrm{s}_{\mathrm{m}}-\mathrm{t}_{\mathrm{m}}\right)+\mathrm{H}\left(\mathrm{t}_{\mathrm{m}+1}-\mathrm{s}_{\mathrm{m}}\right) \leq \mathcal{K}_{\mathrm{m}} \mathrm{T}+\mathrm{HT},
$$

and for $\mathrm{t} \in\left(\mathrm{s}_{\mathrm{m}}, \mathrm{t}_{\mathrm{m}}\right]$, we have that $\|\mathrm{Qu}(\mathrm{t})\| \leq \mathcal{K}_{\mathrm{m}} \mathrm{T}$. We choose $\mathrm{R}=\max \left[\mathcal{K}_{\delta} \mathrm{T}+\mathrm{HT}, \sup _{\mathrm{m}=1, \cdots, \delta}\left\{\mathcal{K}_{\mathrm{m}} \mathrm{T}+\right.\right.$ $\mathrm{HT}\}$ ]. Thus, we get that $\mathrm{Q}(\mathcal{S}) \subseteq \mathcal{S}$. In the next step, we prove that $\mathrm{Q}$ is a contraction map. For $w_{1}, w_{2} \in \mathcal{S}$ and $\mathrm{t} \in\left[0, \mathrm{t}_{1}\right]$, we get

$$
\begin{aligned}
\left\|\mathrm{Q} w_{1}(\mathrm{t})-\mathrm{Q} w_{2}(\mathrm{t})\right\| \leq & {\left[\mathrm{L}_{\mathrm{G}_{\delta}}\left(\mathrm{s}_{\delta}-\mathrm{t}_{\delta}\right)+\mathrm{L}_{\mathrm{f}}\left(1+\mathrm{L}_{\mathrm{h}} \mathcal{L}\right)\left(\mathrm{T}-\mathrm{s}_{\delta}+\mathrm{t}_{1}\right)\right] } \\
& \times\left\|w_{1}-w_{2}\right\|_{\mathcal{P C}} .
\end{aligned}
$$

For $t \in\left[s_{m}, t_{m+1}\right], m=1, \cdots, \delta$

$$
\begin{aligned}
\left\|\mathrm{Q} w_{1}(\mathrm{t})-\mathrm{Q} w_{2}(\mathrm{t})\right\| \leq & {\left[\mathrm{L}_{\mathrm{G}_{\mathrm{m}}}\left(\mathrm{s}_{\mathrm{m}}-\mathrm{t}_{\mathrm{m}}\right)+\mathrm{L}_{\mathrm{f}}\left(1+\mathrm{L}_{\mathrm{h}} \mathcal{L}\right)\left(\mathrm{t}_{\mathrm{m}+1}-\mathrm{s}_{\mathrm{m}}\right)\right]\left\|w_{1}-w_{2}\right\|_{\mathcal{P C}} } \\
\leq & \max _{\mathrm{m}=1, \cdots, \delta}\left[\mathrm{L}_{\mathrm{G}_{\mathrm{m}}}\left(\mathrm{s}_{\mathrm{m}}-\mathrm{t}_{\mathrm{m}}\right)+\mathrm{L}_{\mathrm{f}}\left(1+\mathrm{L}_{\mathrm{h}} \mathcal{L}\right)\left(\mathrm{t}_{\mathrm{m}+1}-\mathrm{s}_{\mathrm{m}}\right)\right] \\
& \times\left\|w_{1}-w_{2}\right\|_{\mathcal{P C}},
\end{aligned}
$$

and for $t \in\left(t_{m}, s_{m}\right]$, we obtain that

$$
\left\|\mathrm{Q} w_{1}(\mathrm{t})-\mathrm{Q} w_{2}(\mathrm{t})\right\| \leq \max _{\mathrm{m}=1, \cdots, \delta} \mathrm{L}_{\mathrm{G}_{\mathrm{m}}}\left(\mathrm{s}_{\mathrm{m}}-\mathrm{t}_{\mathrm{m}}\right) \times\left\|w_{1}-w_{2}\right\|_{\mathcal{P C}}
$$

From the inequalities (3.10)-(3.12), we get

$$
\left\|\mathrm{Q} w_{1}-\mathrm{Q} w_{2}\right\|_{\mathrm{PC}} \leq \Theta\left\|w_{1}-w_{2}\right\|_{\mathcal{P C}} .
$$

Thus, by the inequality (3.3), we conclude that $\mathrm{Q}$ is a contraction on $\mathcal{S}$ and there exists a unique fixed point $\mathfrak{u} \in \mathcal{S}$ of the map $\mathrm{Q}$. It is obvious that $\mathfrak{u}$ is a mild solution for the system (1.1)-(1.3).

Our second existence result is based on Krasnoselskii's theorem. The statement of the theorem is given as: 
Theorem 3.2. Let $F \subset X$ be a closed convex and nonempty subset of $X$, where $X$ is a Banach space. Let $P_{1}$ and $P_{2}$ be the operator such that

(a) $P_{1} w_{1}+P_{2} w_{2} \in F$, whenever, $w_{1}, w_{2} \in F$,

(b) $\mathrm{P}_{1}$ is a contraction,

(c) $\mathrm{P}_{2}$ is compact and continuous.

Then, the map $P=P_{1}+P_{2}$ has a fixed point $x \in F$ i.e., $x=P_{1} x+P_{2} x$.

Theorem 3.3. Assume that $(A 1)-(A 3)$ are satisfied. Then, there exists a mild solution for the system (1.1)-(1.3) on J provided that

$$
\Xi=\max \left\{\mathrm{K}_{\mathrm{G}_{\mathrm{m}}}\left(\mathrm{s}_{\mathrm{m}}-\mathrm{t}_{\mathrm{m}}\right) ; \mathrm{m}=1, \cdots, \delta\right\}<1 .
$$

Proof. We define the following operators $\mathrm{Q}_{1}: \mathcal{S} \rightarrow \mathcal{S}$ which is decomposition of operator $\mathcal{Q}$, by

$$
Q_{1} u(t)= \begin{cases}\int_{t_{\delta}}^{s_{\delta}} G_{\delta}(s, u(s)) d s, & t \in\left[0, t_{1}\right], \\ \int_{s_{m}}^{t} G_{m}(s, u(s)) d s, & t \in\left(t_{m}, s_{m}\right], m=1, \cdots, \delta, \\ \int_{t_{m}}^{s_{m}} G_{m}\left(s_{m}, u\left(s_{m}\right)\right), & t \in\left(s_{m}, t_{m+1}\right] m=1, \cdots, \delta .\end{cases}
$$

and $\mathrm{Q}_{2}: \mathcal{S} \rightarrow \mathcal{S}$ by

$$
Q_{2} u(t)=\left\{\begin{array}{l}
\int_{s_{\delta}}^{T} f(s, u(s), u(h(u(s), s))) d s+\int_{0}^{t} f(s, u(s), u(h(u(s), s))) d s, t \in\left[0, t_{1}\right], \\
0, \quad t \in\left(t_{m}, s_{m}\right], m=1, \cdots, \delta, \\
\int_{s_{m}}^{t} f(s, u(s), u(h(u(s), s))) d s, \quad t \in\left(s_{m}, t_{m+1}\right] i=1, \cdots, \delta .
\end{array}\right.
$$

We choose $r$ such that

$$
\max \left\{\max _{\mathrm{m}=1, \cdots, \delta}\left(\mathcal{K}_{\mathrm{m}}+\mathrm{H}\right) \mathrm{T},\left(\mathcal{K}_{\delta}+\mathrm{H}\right) \mathrm{T}\right\}<\mathrm{r} .
$$

Consider

$$
\mathrm{B}_{\mathrm{r}}=\left\{\mathrm{u} \in \mathrm{Y}_{0} \cap \mathrm{Y}_{1}:\|\mathrm{u}\|_{\mathcal{P C}} \leq \mathrm{r}\right\} .
$$

It is clear that the mappings $\mathcal{Q}_{1}$ and $\mathcal{Q}_{2}$ are well-defined. Now, we show the result in several steps.

Step 1. For $u, v \in B_{r}$ and $t \in\left[0, t_{1}\right]$, we have

$$
\begin{aligned}
\left\|\left(Q_{1} u+Q_{2} v\right)(t)\right\| \leq & \left\|\int_{t_{\delta}}^{s_{\delta}} G_{\delta}(s, u(s)) d s\right\|+\int_{s_{\delta}}^{T}\|f(s, v(s), v(h(v(s), s)))\| d s \\
& +\int_{0}^{t}\|f(s, v(s), v(h(v(s), s)))\| d s \\
\leq & \mathcal{K}_{\delta}\left(s_{\delta}-t_{\delta}\right)+H\left[T-s_{\delta}-t_{1}\right] \leq \mathcal{K}_{\delta} T+H T .
\end{aligned}
$$

For $\mathrm{t} \in\left(\mathrm{s}_{\mathrm{m}}, \mathrm{t}_{\mathrm{m}+1}\right], \mathrm{m}=1, \cdots, \delta$,

$$
\begin{aligned}
\left\|\left(Q_{1} u+Q_{2} v\right)(t)\right\| & \leq\left\|\int_{t_{m}}^{s_{m}} G_{m}(s, u(s)) d s\right\|+\int_{s_{m}}^{t}\|f(s, u(s), u(h(u(s), s)))\| d s \\
& \leq \mathcal{K}_{m}\left(s_{m}-t_{m}\right)+H\left(t_{m+1}-s_{m}\right) \leq\left(\mathcal{K}_{m}+H\right) T
\end{aligned}
$$


and for $t \in\left[t_{m}, s_{m}\right]$, we have $\left\|\left(Q_{1} u+Q_{2} v\right)(t)\right\| \leq \mathcal{K}_{m} T$. Thus, by the choice of $r$, we get that

$$
\left\|\left(Q_{1} u+Q_{2} v\right)\right\|_{\mathcal{P C}} \leq r, \quad \text { for all } t \in[0, T] .
$$

Hence, $\mathrm{Q}_{1} \mathrm{u}+\mathrm{Q}_{2} v \in \mathrm{B}_{\mathrm{r}}$.

Step 2. We show that $Q_{1}$ is contraction map. For $w_{1}, w_{2} \in B_{r}$ and $t \in\left[0, t_{1}\right]$,

$$
\begin{aligned}
\left\|\mathrm{Q}_{1} w_{1}(\mathrm{t})-\mathrm{Q}_{2} w_{2}(\mathrm{t})\right\| & \leq \mathrm{K}_{\mathrm{G}_{\delta}}\left\|w_{1}\left(\mathrm{~s}_{\delta}\right)-w_{2}\left(\mathrm{~s}_{\delta}\right)\right\| \times\left|\mathrm{s}_{\delta}-\mathrm{t}_{\delta}\right| \\
& \leq \mathrm{K}_{\mathrm{G}_{\delta}}\left(\mathrm{s}_{\delta}-\mathrm{t}_{\delta}\right)\left\|w_{1}-w_{2}\right\|_{\mathrm{PC}} .
\end{aligned}
$$

For $t \in\left(t_{m}, s_{m}\right], m=1, \cdots, \delta$, we get

$$
\left\|\mathrm{Q}_{1} w_{1}(\mathrm{t})-\mathrm{Q}_{2} w_{2}(\mathrm{t})\right\| \leq \mathrm{K}_{\mathrm{G}_{\mathrm{m}}}\left(\mathrm{s}_{\mathrm{m}}-\mathrm{t}_{\mathrm{m}}\right)\left\|w_{1}-w_{2}\right\|_{\mathrm{PC}}
$$

and $\mathrm{t} \in\left(\mathrm{s}_{\mathrm{m}}, \mathrm{t}_{\mathrm{m}+1}\right], \mathrm{m}=1, \cdots, \delta$

$$
\left\|\mathrm{Q}_{1} w_{1}(\mathrm{t})-\mathrm{Q}_{2} w_{2}(\mathrm{t})\right\| \leq \mathrm{K}_{\mathrm{G}_{\mathrm{m}}}\left(\mathrm{s}_{\mathrm{m}}-\mathrm{t}_{\mathrm{m}}\right)\left\|w_{1}-w_{2}\right\|_{\mathrm{PC}} .
$$

From the above inequalities, we conclude that

$$
\left\|\mathrm{Q}_{1} w_{1}-\mathrm{Q}_{2} w_{2}\right\|_{\mathrm{PC}} \leq \Xi\left\|w_{1}-w_{2}\right\|_{\mathrm{PC}}
$$

which gives that $\mathrm{Q}_{1}$ is a contraction.

Step 3. $\mathrm{Q}_{2}$ is continuous map. Let $\left\{z_{\mathfrak{p}}\right\}_{\mathfrak{p}=1}^{\infty}$ be a sequence such that $z_{\mathfrak{p}} \rightarrow z \in \mathrm{B}_{\mathrm{r}}$. For $\mathrm{t} \in\left[0, \mathrm{t}_{1}\right]$,

$$
\begin{aligned}
\left\|\mathrm{Q}_{2} z_{\mathfrak{p}}(\mathrm{t})-\mathrm{Q}_{2} z(\mathrm{t})\right\| \leq & \int_{\mathrm{s}_{\delta}}^{\mathrm{T}}\left\|\mathrm{f}\left(\mathrm{s}, z_{\mathrm{p}}(\mathrm{s}), z_{\mathfrak{p}}\left(\mathrm{h}\left(z_{\mathfrak{p}}(\mathrm{s}), \mathrm{s}\right)\right)\right)-\mathrm{f}(\mathrm{s}, z(\mathrm{~s}), z(\mathrm{~h}(z(\mathrm{~s}), \mathrm{s})))\right\| \mathrm{d} s \\
& +\int_{0}^{\mathrm{t}}\left\|\mathrm{f}\left(\mathrm{s}, z_{\mathfrak{p}}(\mathrm{s}), z_{\mathfrak{p}}\left(\mathrm{h}\left(z_{\mathfrak{p}}(\mathrm{s}), \mathrm{s}\right)\right)\right)-\mathrm{f}(\mathrm{s}, z(\mathrm{~s}), z(\mathrm{~h}(z(\mathrm{~s}), \mathrm{s})))\right\| \mathrm{ds}
\end{aligned}
$$

by the continuity of $f$ and $h$, we have that $s \in[0, t]$

$$
\begin{aligned}
\mathrm{f}\left(\mathrm{s}, z_{\mathrm{p}}(\mathrm{s}), z_{\mathrm{p}}\left(\mathrm{h}\left(z_{\mathrm{p}}(\mathrm{s}), \mathrm{s}\right)\right)\right) & \rightarrow \mathrm{f}(\mathrm{s}, z(\mathrm{~s}), z(\mathrm{~h}(z(\mathrm{~s}), \mathrm{s}))), \text { as } \mathrm{p} \rightarrow \infty \\
\mathrm{h}\left(z_{\mathrm{p}}(\mathrm{s}), \mathrm{s}\right) & \rightarrow \mathrm{h}(z(\mathrm{~s}), \mathrm{s}), \quad \text { as } \mathrm{p} \rightarrow \infty
\end{aligned}
$$

From the dominated convergence theorem, we get

$$
\left\|\mathrm{Q}_{2} z_{\mathrm{p}}-\mathrm{Q}_{2} z\right\|_{\mathrm{PC}} \rightarrow 0, \quad \text { as } \mathrm{p} \rightarrow \infty,
$$

For $t \in\left(t_{m}, s_{m}\right], m=1, \cdots, \delta$,

$$
\left\|\mathrm{Q}_{2} z_{\mathrm{p}}(\mathrm{t})-\mathrm{Q}_{2} z(\mathrm{t})\right\|=0 .
$$

Similarly, for $\mathrm{t} \in\left(\mathrm{s}_{\mathrm{m}}, \mathrm{t}_{\mathrm{m}+1}\right], \mathrm{m}=1, \cdots, \delta$

$$
\left\|\mathrm{Q}_{2} z_{\mathfrak{p}}(\mathrm{t})-\mathrm{Q}_{2} z(\mathrm{t})\right\| \leq \int_{s_{\mathrm{m}}}^{\mathrm{t}}\left\|\mathrm{f}\left(\mathrm{s}, z_{\mathrm{p}}(\mathrm{s}), z_{\mathrm{p}}\left(\mathrm{h}\left(z_{\mathfrak{p}}(\mathrm{s}), \mathrm{s}\right)\right)\right)-\mathrm{f}(\mathrm{s}, z(\mathrm{~s}), z(\mathrm{~h}(z(\mathrm{~s}), \mathrm{s})))\right\| \mathrm{ds},
$$


by the continuity of $f, h$ and the dominated convergence theorem, we deduce that

$$
\left\|\mathrm{Q}_{2} z_{\mathrm{p}}-\mathrm{Q}_{2} z\right\|_{\mathrm{PC}} \rightarrow 0, \quad \text { as } \mathrm{p} \rightarrow \infty
$$

Step 3. $\mathrm{Q}_{2}$ is compact.

Since $f$ is continuous map and $\left\|\left(Q_{2} u\right)(t)\right\| \leq 2 H T<r$. This implies that $Q_{2}$ is uniformly bounded on $B_{r}$. Now, we show that $Q_{2}$ maps bounded set into equicontinuous set of $B_{r}$. For $\tau_{2}>\tau_{1} \in\left[0, t_{1}\right]$ and $u \in B_{r}$, we have

$$
\left\|\mathrm{Q}_{2} \mathrm{u}\left(\tau_{2}\right)-\mathrm{Q}_{2} \mathrm{u}\left(\tau_{1}\right)\right\| \leq \mathrm{L}_{\mathrm{F}}\left(\tau_{2}-\tau_{1}\right)
$$

For $\tau_{2}>\tau_{1} \in\left(t_{m}, s_{m}\right]$, we have

$$
\left\|Q_{2} u\left(\tau_{2}\right)-Q_{2} u\left(\tau_{1}\right)\right\|=0
$$

For $\tau_{2}>\tau_{1} \in\left(s_{m}, t_{m+1}\right], m=1, \cdots, \delta$ and $u \in B_{r}$, we have

$$
\left\|\mathrm{Q}_{2} \mathrm{u}\left(\tau_{2}\right)-\mathrm{Q}_{2} \mathrm{u}\left(\tau_{1}\right)\right\| \leq \mathrm{L}_{\mathrm{F}}\left(\tau_{2}-\tau_{1}\right)
$$

Thus, we conclude that $\left\|\mathrm{Q}_{2} u\left(\tau_{2}\right)-\mathrm{Q}_{2} \mathrm{u}\left(\tau_{1}\right)\right\| \rightarrow 0$ as $\tau_{2} \rightarrow \tau_{1}$. Hence $\mathrm{Q}_{2}$ is equicontinuous.

By the Steps (3) - (4) and Arzela-Ascoli theorem, we deduce that $Q_{2}: B_{r} \rightarrow B_{r}$ is continuous and compact i.e. completely continuous. Since $\mathrm{Q}_{1}$ is contraction and $\mathrm{Q}_{2}$ is completely continuous operator. Thus, $\mathrm{Q}=\mathrm{Q}_{1}+\mathrm{Q}_{2}$ has a fixed point by using Krasnoselskiis fixed point theorem which is just a mild solution for the system (1.1)-(1.3). The proof of the theorem is finished.

\subsection{Fractional order case}

Now, we obtain the existence results for the problem (1.4)-(1.6) via fixed points theorems, the first existence result of the mild solution for problem (1.4)-(1.6) is obtained by using Banach fixed point theorem and second existence results is obtained by using Krasnoselskii's fixed point theorem.

Theorem 3.4. Assume that hypotheses $(A 1)-(A 3)$ are fulfilled and

$$
\begin{array}{r}
\Lambda=\sup \left\{\max _{m=1, \cdots, \delta}\left[L_{G_{m}}\left(s_{m}-t_{m}\right)+\frac{L_{f}\left(1+\mathcal{L} L_{h}\right)\left(t_{m+1}^{2}+s_{m}^{2}\right)}{2}\right], \max _{m=1, \cdots . \delta}\left(s_{m}-t_{m}\right) L_{G_{m}},\right. \\
L_{G_{\delta}}\left(s_{\delta}-t_{\delta}\right)+\frac{L_{f}\left(1+\mathcal{L} L_{h}\right)\left(T^{2}+s_{\delta}^{2}+t_{1}^{2}\right.}{2}<1 .
\end{array}
$$

Then, the problem (1.4)-(1.6) has at least one mild solution on $[0, \mathrm{~T}]$.

Proof. We firstly define the operator $\mathcal{Q}: \mathcal{S} \rightarrow \mathcal{S}$ by

$$
(\mathcal{Q} u)(t)=\left\{\begin{array}{l}
\int_{t_{\delta}}^{s_{\delta}} G_{\delta}(s, u(s)) d s-\int_{0}^{s_{\delta}}\left(s_{\delta}-s\right) f(s, u(s), u([h(u(s), s)])) d s \\
+\int_{0}^{T}(T-s) f(s, u(s), u([h(u(s), s)])) d s \\
+\int_{0}^{t}(t-s) f(s, u(s), u([h(u(s), s)])) d s, \quad t \in\left[0, t_{1}\right] \\
\int_{t_{m}}^{t} G_{m}(s, u(s)) d s, \quad t \in\left(t_{m}, s_{m}\right], m=1, \cdots, \delta \\
\int_{t_{m}}^{s_{m}} G_{m}(s, u(s)) d s-\int_{0}^{s_{m}}\left(s_{m}-s\right) f(s, u(s), u([h(u(s), s)])) d s \\
+\int_{0}^{t}(t-s) f(s, u(s), u([h(u(s), s)])) d s, t \in\left(s_{m}, t_{m+1}\right], m=1, \cdots, \delta .
\end{array}\right.
$$


It is clear that $\mathcal{Q} u \in Y_{0}$. So it remains to show that $\mathcal{Q u} \in \mathrm{Y}_{1}$. For $\mathfrak{u} \in \mathcal{S}$ and $\tau_{2}, \tau_{1} \in\left[0, t_{1}\right]$ with $\tau_{1} \leq \tau_{2}$, we get

$$
\begin{aligned}
\|(\mathcal{Q u})\left(\tau_{2}\right)- & (\mathcal{Q u})\left(\tau_{1}\right) \| \\
= & \left\|\int_{0}^{\tau_{2}}\left(\tau_{2}-s\right) f(s, u(s), u([h(u(s), s)])) d s-\int^{\tau_{1}}\left(\tau_{1}-s\right) f(s, u(s), u([h(u(s), s)])) d s\right\|, \\
\leq & \left\|\int_{0}^{\tau_{1}}\left[\left(\tau_{2}-s\right)-\left(\tau_{1}-s\right)\right] f(s, u(s), u([h(u(s), s)])) d s\right\| \\
& +\left\|\int_{\tau_{1}}^{\tau_{2}}\left(\tau_{2}-s\right) f(s, u(s), u([h(u(s), s)])) d s\right\|, \\
\leq & H\left(\tau_{2}-\tau_{1}\right)^{2}+H \frac{\left(\tau_{2}-\tau_{1}\right)^{2}}{2}, \\
\leq & 2 H T\left|\tau_{2}-\tau_{1}\right|,
\end{aligned}
$$

Similarly, for $\tau_{2}, \tau_{1} \in\left(s_{m}, t_{m+1}\right], m=1, \cdots, \delta$,

$$
\left\|(\mathcal{Q u})\left(\tau_{2}\right)-(\mathcal{Q u})\left(\tau_{1}\right)\right\| \leq \mathrm{HT}\left|\tau_{2}-\tau_{1}\right|
$$

and for $\tau_{2}, \tau_{1} \in\left(t_{m}, s_{m}\right]$,

$$
\left\|(\mathcal{Q u})\left(\tau_{2}\right)-(\mathcal{Q u})\left(\tau_{1}\right)\right\| \leq \mathcal{K}_{m}\left|\tau_{2}-\tau_{1}\right|
$$

Thus, from (3.32)-(3.34), we conclude that $\mathcal{Q u} \in \mathrm{Y}_{1}$ with $\mathcal{L}=\min \left\{\max _{\mathrm{m}=1, \cdots, \delta} \mathcal{K}_{\mathrm{m}}, 2 \mathrm{HT}, \mathrm{HT}\right\}$. Hence $\mathcal{Q}$ is well defined on $\mathcal{S}$. Next we show that $\mathcal{Q}(\mathcal{S}) \subseteq \mathcal{S}$. For $\mathfrak{u} \in \mathcal{S}$ and $\mathrm{t} \in\left[0, \mathrm{t}_{1}\right]$, we get

$$
\begin{aligned}
\|\mathcal{Q u}(\mathrm{t})\| \leq & \left\|\int_{\mathrm{t}_{\delta}}^{s_{\delta}} \mathrm{G}_{\delta}(\mathrm{s}, \mathrm{u}(\mathrm{s})) \mathrm{ds}\right\|+\int_{0}^{s_{\delta}}\left(\mathrm{s}_{\delta}-\mathrm{s}\right)\|f(s, u(s), \mathfrak{u}([\mathrm{h}(\mathrm{u}(\mathrm{s}), \mathrm{s})]))\| \mathrm{ds} \\
& +\int_{0}^{T}(\mathrm{~T}-\mathrm{s})\|\mathrm{f}(\mathrm{s}, \mathrm{u}(\mathrm{s}), \mathfrak{u}([\mathrm{h}(\mathrm{u}(\mathrm{s}), \mathrm{s})]))\| \mathrm{ds} \\
& +\int_{0}^{\mathrm{t}}(\mathrm{t}-\mathrm{s}) \mathrm{f}(\mathrm{s}, \mathrm{u}(\mathrm{s}), \mathfrak{u}([\mathrm{h}(\mathrm{u}(\mathrm{s}), \mathrm{s})])) \mathrm{ds}, \\
\leq & \mathcal{K}_{\delta}\left(\mathrm{s}_{\delta}-\mathrm{t}_{\delta}\right)+\frac{\mathrm{H}\left(\mathrm{T}^{2}+\mathrm{s}_{\delta}^{2}+\mathrm{t}_{1}^{2}\right)}{2} \leq \mathcal{K}_{\delta} \mathrm{T}+\frac{3 \mathrm{HT}^{2}}{2} .
\end{aligned}
$$

Similarly, for $t \in\left(s_{m}, t_{m+1}\right], m=1, \cdots, \delta$,

$$
\|\mathcal{Q u}(\mathrm{t})\| \leq \mathcal{K}_{\mathrm{m}} \mathrm{T}+\mathrm{T}^{2} \mathrm{H},
$$

and for $t \in\left(t_{m}, s_{m}\right]$, we get

$$
\|\mathcal{Q u}(\mathrm{t})\| \leq \mathcal{K}_{\mathrm{m}} \mathrm{T}
$$

We choose $R=\max \left\{\mathcal{K}_{\delta} T+\frac{3 T^{2} H}{2}, \sup _{m=1, \cdots, \delta} \mathcal{K}_{m} T+T^{2} H\right\}$ such that $\|\mathcal{Q u}(t)\| \leq R$, for all $\mathrm{t} \in[0, T]$. We now show that $\mathcal{Q}$ is a contraction map on $\mathcal{S}$. For $\mathrm{u}^{*}, \mathrm{u}^{* *} \in \mathcal{S}$ and $\mathrm{t} \in\left[0, \mathrm{t}_{1}\right]$, we get 


$$
\begin{aligned}
\|\left(\mathcal{Q} u^{*}\right)(t)- & \left(\mathcal{Q} u^{* *}\right)(t) \| \\
\leq & \left\|\int_{t_{\delta}}^{s_{\delta}}\left[G_{\delta}\left(s, u^{*}(s)\right)-G_{\delta}\left(s, u^{* *}(s)\right)\right] d s\right\| \\
& +\int_{0}^{s_{\delta}}\left(s_{\delta}-s\right)\left\|f\left(s, u^{*}(s), u^{*}\left(\left[h\left(u^{*}(s), s\right)\right]\right)\right)-f\left(s, u^{* *}(s), u^{* *}\left(\left[h\left(u^{* *}(s), s\right)\right]\right)\right)\right\| d s \\
& +\int_{0}^{T}(T-s)\left\|f\left(s, u^{*}(s), u^{*}\left(\left[h\left(u^{*}(s), s\right)\right]\right)\right)-f\left(s, u^{* *}(s), u^{* *}\left(\left[h\left(u^{* *}(s), s\right)\right]\right)\right)\right\| d s \\
& +\int_{0}^{t}(t-s)\left\|f\left(s, u^{*}(s), u^{*}\left(\left[h\left(u^{*}(s), s\right)\right]\right)\right)-f\left(s, u^{* *}(s), u^{* *}\left(\left[h\left(u^{* *}(s), s\right)\right]\right)\right)\right\| d s \\
\leq & {\left[L_{G_{\delta}}\left(s_{\delta}-t_{\delta}\right)+\frac{L_{f}\left(1+\mathcal{L} L_{h}\right)\left(T^{2}+s_{\delta}^{2}+t_{1}^{2}\right.}{2}\right]\left\|u^{*}-u^{* *}\right\|_{\mathcal{P C} \cdot} }
\end{aligned}
$$

Similarly, for $t \in\left(s_{m}, t_{m+1}\right], m=1, \cdots, \delta$

$\left\|\left(\mathcal{Q} u^{*}\right)(\mathrm{t})-\left(\mathcal{Q} u^{* *}\right)(\mathrm{t})\right\|$

$$
\begin{aligned}
\leq & \left\|\int_{t_{m}}^{s_{m}}\left[G_{m}\left(s, u^{*}(s)\right)-G_{m}\left(s, u^{* *}(s)\right)\right] d s\right\| \\
& +\int_{0}^{s_{m}}\left(s_{m}-s\right)\left\|f\left(s, u^{*}(s), u^{*}\left(\left[h\left(u^{*}(s), s\right)\right]\right)\right)-f\left(s, u^{* *}(s), u^{* *}\left(\left[h\left(u^{* *}(s), s\right)\right]\right)\right)\right\| d s \\
& +\int_{0}^{t}(t-s)\left\|f\left(s, u^{*}(s), u^{*}\left(\left[h\left(u^{*}(s), s\right)\right]\right)\right)-f\left(s, u^{* *}(s), u^{* *}\left(\left[h\left(u^{* *}(s), s\right)\right]\right)\right)\right\| d s \\
\leq \quad & \max _{m=1, \cdots, \delta}\left[L_{G_{m}}\left(s_{m}-t_{m}\right)+\frac{L_{f}\left(1+\mathcal{L} L_{h}\right)\left(t_{m+1}^{2}+s_{m}^{2}\right)}{2}\right]\left\|u^{*}-u^{* *}\right\|_{\mathcal{P C}},
\end{aligned}
$$

and for $t \in\left(t_{m}, s_{m}\right)$, we get

$$
\left\|\left(\mathcal{Q} u^{*}\right)(t)-\left(\mathcal{Q} u^{* *}\right)(t)\right\| \leq \max _{m=1, \cdots . \delta} L_{G_{m}}\left(s_{m}-t_{m}\right)\left\|u^{*}-u^{* *}\right\|_{\mathcal{P C}} .
$$

From the inequalities (3.38)-(3.40), we obtain

$$
\left\|\left(\mathcal{Q} u^{*}\right)(t)-\left(\mathcal{Q} u^{* *}\right)(t)\right\| \leq \Lambda\left\|u^{*}-u^{* *}\right\|_{\mathcal{P C}}
$$

Thus, by the inequality (3.30), we conclude that $\mathcal{Q}$ is a contraction on $\mathcal{S}$ i.e., there exists a unique fixed point of the map $u \in \mathcal{S}$ such that $\mathcal{Q} u(t)=u(t)$ for all $t \in[0, T]$. Hence problem (1.4)-(1.6) has a unique mild solution on $[0, T]$.

Theorem 3.5. Assume that $(A 1)-(A 3)$ are fulfilled and

$$
\Xi=\max \left\{\mathrm{L}_{\mathrm{G}_{\mathrm{m}}}\left|\mathrm{s}_{\mathrm{m}}-\mathrm{t}_{\mathrm{m}}\right| ; \mathrm{m}=1, \cdots, \delta\right\}<1 .
$$

Then, problem (1.4)-(1.6) has at least one mild solution on $[0, \mathrm{~T}]$.

Proof. We consider the operators $\mathcal{Q}_{1}$ and $\mathcal{Q}_{2}$ on $B_{\mathrm{q}, \mathrm{r}}=\left\{\mathrm{u} \in \mathrm{Y}_{0} \cap \mathrm{Y}_{1}:\|\mathrm{u}\|_{\mathcal{P C}} \leq \mathrm{r}\right\}$ defined by

$$
\mathcal{Q}_{1} u(t)=\left\{\begin{array}{l}
\int_{t_{m}}^{t} G_{m}(s, u(s)) d s, \quad t \in\left(t_{m}, s_{m}\right], \\
\int_{t_{\delta}}^{s_{\delta}} G_{\delta}(s, u(s)) d s, \quad t \in\left[0, t_{1}\right] \\
\int_{t_{m}}^{s_{m}} G_{m}(s, u(s)) d s, \quad t \in\left(s_{m}, t_{m+1}\right], \quad m=1, \ldots, \delta,
\end{array}\right.
$$


and

$$
\mathcal{Q}_{2} u(t)= \begin{cases}\int_{0}^{T}(T-s) f(s, u(s), u([h(u(s), s)])) d s & \\ -\int_{0}^{s_{\delta}}\left(s_{\delta}-s\right) f(s, u(s), u([h(u(s), s)])) d s & \\ +\int_{0}^{t}(t-s) f(s, u(s), u([h(u(s), s)])) d s, & t \in\left[0, t_{1}\right] \\ 0, & t \in\left(t_{m}, s_{m}\right], \quad m=1, \cdots, \delta \\ -\int_{0}^{s_{m}}\left(s_{m}-s\right) f(s, u(s), u([h(u(s), s)])) d s \\ +\int_{0}^{t}(t-s) f(s, u(s), u([h(u(s), s)])) d s, & t \in\left(s_{m}, t_{m+1}\right], \quad m=1, \cdots, \delta .\end{cases}
$$

where $r$ is a positive constant such that

$$
\max \left\{\sup _{\mathrm{m}=1, \cdots, \delta} \mathcal{K}_{\mathrm{m}}\left(\mathrm{s}_{\mathrm{m}}-\mathrm{t}_{\mathrm{m}}\right)+\frac{\mathrm{H}\left(\mathrm{t}_{\mathrm{m}+1}^{2}+\mathrm{s}_{\mathrm{m}}^{2}\right)}{2}, \mathcal{K}_{\delta}\left(\mathrm{s}_{\delta}-\mathrm{t}_{\delta}\right)+\frac{\mathrm{H}\left(\mathrm{T}^{2}+\mathrm{s}_{\delta}^{2}+\mathrm{t}_{1}^{2}\right)}{2}\right\} \leq \mathrm{r} .
$$

For the purpose of convenience, we separate the proof into a few steps.

Step 1. We show that $\mathcal{Q}_{1} u+\mathcal{Q}_{2} u \in B_{\mathrm{q}, \mathrm{r}}$ for each $u \in \mathrm{B}_{\mathrm{q}, \mathrm{r}}$.

For $t \in\left[0, t_{1}\right]$, we have

$\left\|\mathcal{Q}_{1} u(t)+\mathcal{Q}_{2} u(t)\right\|$

$$
\begin{aligned}
\leq & \left\|\int_{t_{\delta}}^{s_{\delta}} G_{\delta}(s, u(s)) d s\right\|+\left\|\int_{0}^{T}(T-s) f(s, u(s), u([h(u(s), s)])) d s\right\| \\
& +\left\|\int_{0}^{s_{\delta}}\left(s_{\delta}-s\right) f(s, u(s), u([h(u(s), s)])) d s\right\|+\left\|\int_{0}^{t}(t-s) f(s, u(s), u([h(u(s), s)])) d s\right\| \\
\leq & \mathcal{K}_{\delta}\left(s_{\delta}-t_{\delta}\right)+\frac{H\left(T^{2}+s_{\delta}^{2}+t_{1}^{2}\right)}{2}
\end{aligned}
$$

where $H=\sup _{t \in[0, T]}\|f(t, u(t), \mathfrak{u}([h(u(t), t)]))\|$. Similarly, for $t \in\left(s_{\mathfrak{m}}, t_{\mathfrak{m}+1}\right], \mathfrak{m}=1, \cdots, \delta$ $\left\|\mathcal{Q}_{1} \mathrm{u}(\mathrm{t})+\mathcal{Q}_{2} \mathrm{u}(\mathrm{t})\right\|$

$$
\begin{aligned}
\leq & \left\|\int_{t_{m}}^{s_{m}} G_{m}\left(t_{m}, u\left(t_{m}\right)\right)\right\|+\left\|\int_{0}^{s_{m}}\left(s_{m}-s\right) f(s, u(s), u([h(u(s), s)])) d s\right\| \\
& +\left\|\int_{0}^{t}(t-s) f(s, u(s), u([h(u(s), s)])) d s\right\|, \\
\leq & \mathcal{K}_{m}\left(s_{m}-t_{m}\right)+\frac{H\left(t_{m+1}^{2}+s_{m}^{2}\right)}{2},
\end{aligned}
$$

and for $\mathrm{t} \in\left(\mathrm{t}_{\mathrm{m}}, \mathrm{s}_{\mathrm{m}}\right], \mathrm{m}=1, \cdots, \delta$,

$$
\left\|\mathcal{Q}_{1} u(t)+\mathcal{Q}_{2} u(t)\right\| \leq \mathcal{K}_{m}\left(s_{m}-t_{m}\right) .
$$

By inequality (3.45), we get $\left\|\mathcal{Q}_{1} u(t)+\mathcal{Q}_{2} u(t)\right\| \leq r$ for all $\mathrm{t} \in[0, \mathrm{~T}]$. Hence, $\mathcal{Q}_{1} u+\mathcal{Q}_{2} u \in B_{\mathrm{q}, \mathrm{r}}$. Step 2. The map $\mathcal{Q}_{1}$ is contraction on $\mathrm{B}_{\mathrm{q}, \mathrm{r}}$.

From the step 2 of Theorem 3.3, we have that $\mathcal{Q}_{1}$ is a contraction on $\mathrm{B}_{\mathrm{q}, \mathrm{r}}$.

Step 3. The map $\mathcal{Q}_{2}$ is continuous on $\mathrm{B}_{\mathrm{q}, \mathrm{r}}$.

Let $\left\{u_{p}\right\}_{p=1}^{\infty}$ be a sequence in $B_{q, r}$ such that $\lim _{p \rightarrow \infty} u_{p}=u \in B_{q, r}$. For $t \in\left(t_{m}, s_{m}\right], m=$ 
$1, \cdots, \delta$, it is obvious since $\mathcal{Q}_{2} \mathrm{u}_{\mathrm{p}}(\mathrm{t})=0$. For $\mathrm{t} \in\left[0, \mathrm{t}_{1}\right]$, we get $\left\|\left(\mathcal{Q}_{2} u_{p}\right)(t)-\left(\mathcal{Q}_{2} u\right)(t)\right\|$

$$
\begin{aligned}
\leq & \int_{0}^{T}(T-s)\left\|f\left(s, u_{p}(s), u_{p}\left(\left[h\left(u_{p}(s), s\right)\right]\right)\right)-f(s, u(s), u([h(u(s), s)]))\right\| d s \\
& +\int_{0}^{s_{\delta}}\left(s_{\delta}-s\right)\left\|f\left(s, u_{p}(s), u_{p}\left(\left[h\left(u_{p}(s), s\right)\right]\right)\right)-f(s, u(s), u([h(u(s), s)]))\right\| d s \\
& +\int_{0}^{t}(t-s)\left\|f\left(s, u_{p}(s), u_{p}\left(\left[h\left(u_{p}(s), s\right)\right]\right)\right)-f(s, u(s), u([h(u(s), s)])) d s\right\| d s
\end{aligned}
$$

by the continuity of $f$ and Lebesgue dominated convergence theorem, we estimate

$$
\left\|\left(\mathcal{Q}_{2} u_{p}\right)(t)-\left(\mathcal{Q}_{2} u\right)(t)\right\| \rightarrow 0, \text { as } p \rightarrow \infty
$$

Similarly, $\mathrm{t} \in\left(\mathrm{s}_{\mathrm{m}}, \mathrm{t}_{\mathrm{m}+1}\right], \mathrm{m}=1, \cdots, \delta$,

$$
\begin{aligned}
\|\left(\mathcal{Q}_{2} u_{p}\right)(t)- & \left(\mathcal{Q}_{2} u\right)(t) \| \\
\leq & \int_{0}^{s_{m}}\left(s_{m}-s\right)\left\|f\left(s, u_{p}(s), u_{p}\left(\left[h\left(u_{p}(s), s\right)\right]\right)\right)-f(s, u(s), u([h(u(s), s)]))\right\| d s \\
& \quad+\int_{0}^{t}(t-s)\left\|f\left(s, u_{p}(s), u_{p}\left(\left[h\left(u_{p}(s), s\right)\right]\right)\right)-f(s, u(s), u([h(u(s), s)]))\right\| d s
\end{aligned}
$$

by the continuity of $f$ and Lebesgue dominated convergence theorem, we estimate

$$
\left\|\left(\mathcal{Q}_{2} u_{p}\right)(t)-\left(\mathcal{Q}_{2} u\right)(t)\right\| \rightarrow 0, \forall t \in \in\left(s_{m}, t_{m+1}\right] \text { as } p \rightarrow \infty
$$

Hence, $\mathcal{Q}_{2}$ is continuous map on $\mathrm{B}_{\mathrm{q}, \mathrm{r}}$.

Step 4. $\mathcal{Q}_{2}$ is compact. $\mathcal{Q}_{2}$ is firstly uniformly bounded on $\mathrm{B}_{\mathrm{q}, \mathrm{r}}$, since $\left\|\mathcal{Q}_{2} \mathrm{u}\right\|_{\mathcal{P C}} \leq \mathrm{r}$. We now prove that $\mathcal{Q}_{2}$ maps bounded set into equicontinuous set of $\mathrm{B}_{\mathrm{q}, \mathrm{r}}$. For $\mathrm{t} \in\left(\mathrm{t}_{\mathrm{m}}, \mathrm{s}_{\mathrm{m}}\right], \mathrm{m}=1, \cdots, \delta$, it is obvious. For $\tau_{2}, \tau_{1} \in\left[0, t_{1}\right]$ with $\tau_{1}<\tau_{2}$, we have

$$
\left\|\mathcal{Q}_{2}\left(\tau_{2}\right)-\mathcal{Q}_{2}\left(\tau_{1}\right)\right\| \leq \mathrm{H}\left(\tau_{2}-\tau_{1}\right)^{2}+\mathrm{H} \frac{\left(\tau_{2}-\tau_{1}\right)^{2}}{2}
$$

For $\tau_{2}, \tau_{1} \in\left(s_{m}, t_{m+1}\right], m=1, \cdots, \delta$ with $\tau_{2}>\tau_{1}$,

$$
\left\|\mathcal{Q}_{2}\left(\tau_{2}\right)-\mathcal{Q}_{2}\left(\tau_{1}\right)\right\| \leq \mathrm{H}\left(\tau_{2}-\tau_{1}\right)^{2}+\mathrm{H} \frac{\left(\tau_{2}-\tau_{1}\right)^{2}}{2}
$$

The right hand side of inequalities (3.51)-(3.52) tend to zero as $\tau_{2} \rightarrow \tau_{1}$. Thus, $\mathcal{Q}_{2}\left(\mathrm{~B}_{\mathrm{q}, \mathrm{r}}\right)$ is equicontinuous. By Arzela-Ascoli theorem, we conclude that $\mathcal{Q}_{2}$ is completely continuous.

Therefore, from the Krasnoselskiis fixed point theorem, we deduce that $\mathcal{Q}=\mathcal{Q}_{1}+\mathcal{Q}_{2}$ has a fixed point which is just a mild solution for the problem (1.4)-(1.6). 


\section{Examples}

For illustrating the application of the theory, we consider the following examples.

Let us consider the following impulsive nonlinear Cauchy problems with boundary conditions as

$$
\begin{aligned}
u^{\prime}(t)\left(\text { or }{ }^{c} D_{0, t}^{1 / 2} u(t)\right) & =\frac{1}{3+t^{3}}\left[\frac{|u(t)|}{6(1+|u(t)|)}+\frac{\left|u\left(\frac{1}{3} u(t)\right)\right|}{1+\left|u\left(\frac{1}{3} u(t)\right)\right|}\right] \\
t \in(0,1] \cup(2,3] & \quad \text { or }\left(I_{0, t}^{3 / 2} \frac{1}{3+t^{3}}\left[\frac{|u(t)|}{6(1+|u(t)|)}+\frac{\left|u\left(\frac{1}{3} u(t)\right)\right|}{1+\left|u\left(\frac{1}{3} u(t)\right)\right|}\right]\right), \\
u(t) & =\int_{1}^{t} \frac{|u(s)|}{(9 s+1)(1+|u(s)|)} d s, \quad t \in(1,2], \\
u(0) & =u(3),
\end{aligned}
$$

where $0=s_{0}<t_{1}=1<s_{1}=2<t_{2}=3$ and $J=[0,3]$ and $u \in C^{1}([0,3],[0,3])$. Then, $u \in C_{L}([0,3],[0,3])$. Here

$$
\mathrm{C}_{\mathrm{L}}([0,3],[0,3])=\left\{u \in C([0,3],[0,3]):|u(t)-u(s)|_{\mathrm{L}} \leq \mathrm{L}|\mathrm{t}-\mathrm{s}|, \quad \forall \mathrm{t}, \mathrm{s} \in[0,3]\right\}
$$

and

$$
\begin{aligned}
f(t, u(t), u(h(u(t), t))) & =\frac{1}{3+t^{3}}\left[\frac{|u(t)|}{6(1+|u(t)|)}+\frac{\left|u\left(\frac{1}{3} u(t)\right)\right|}{1+\left|u\left(\frac{1}{3} u(t)\right)\right|}\right] \\
G_{1}(t, u(t)) & =\frac{|u(t)|}{(9 t+1)(1+|u(t)|)} .
\end{aligned}
$$

It is easy to show that $f$ and $g$ satisfy the following condition

$$
\begin{aligned}
\left\|f\left(t, u_{1}, v_{1}\right)-f\left(t, u_{2}, v_{2}\right)\right\| & \leq L_{f}\left[\left\|u_{1}-u_{2}\right\|+\left\|v_{1}-v_{2}\right\|_{L}\right], u_{1}, u_{2} \in[0,3] \\
\left\|G_{1}\left(t, u_{1}\right)-G_{1}\left(t, u_{2}\right)\right\| & \leq \frac{1}{10}\left\|u_{1}-u_{2}\right\| \\
\left\|G_{1}(t, u)\right\| & \leq \frac{1}{9 t+1}=\mathcal{K}_{1} \leq \frac{1}{10}
\end{aligned}
$$

Thus all the assumptions of Theorem 3.1/3.3 or 3.4/3.5 are fulfilled. Hence, there exists a mild solution for the problem (4.1).

Acknowledgement. The authors would like to thank the referee for valuable comments and suggestions. The work of the first author is supported by the UGC (University Grants Commission, India) under Grant No (6405 - 11-061) and Indian Institute of Technology, Roorkee. nt.

$$
\text { Received: December 2014. Accepted: January } 2015 .
$$




\section{References}

[1] M. Benchohra, J. Henderson, S. K. Ntouyas, Impulsive Differential Equations and Inclusions, Contemporary Mathematics and Its Applications, Vol.2, Hindawi Publishing Corporation, New York, 2006.

[2] V. Lakshmikantham, D. D. Bainov, P.S. Simeonov, Theory of Impulsive Differential Equations, World Scientific, Singapore-London, 1989.

[3] P. Kumar, D. N. Pandey, D. Bahuguna, Impulsive boundary value problems for fractional differential equations with deviating arguments, J. Fract. Cal. Appl. 5 (2014), 146-155.

[4] E. Hernández, D. O'Regan, On a new class of abstract impulsive differential equations, Proc. Amer. Math. Soc., 141 (2012), 1641-1649.

[5] M. Pierri, D. O' Regan, V. Rolnik, Existence of solutions for semilinear abstract differential equation with not instantaneous impulsive, App. Maths. Comput., 219 (2013), 6743-6749.

[6] A. Chadha, D. N. Pandey, Existence of the mild solution for impulsive semilinear differential equation, Int. J. Partial. Diff. Equat., 2014 (2014), Art. ID 640931, pp-8.

[7] J. R. Wang, X. Li, Periodic BVP for integer/fractional order nonlinear differential equations with non-instantaneous impulses, J. Appl. Math. Comput., 2014 (2014), pp-14.

[8] M. Feckan, Y. Zhou, J. Wang, On the concept and existence of solution for impulsive fractional differential equations, Commun. Nonlinear Sci. Numer. Simulat., 17 (2012), 3050-3060.

[9] K. Balachandran, F. C. Samuel, Existence of mild solutions for integrodifferential equations with impulsive conditions, Electr. J. Diff. Equat., 84 (2009), 1-9.

[10] B. Ahmad, S. K. Ntouyas, A. Alsaedi, An existence result for fractional differential inclusions with nonlinear integral boundary conditions, J. Inequalities and Appl., 296 (2013), pp-9.

[11] H. M. Ahmed, A. A. M. Hassan, A. S. Ghanem, Existence of mild solution for impulsive fractional differential equations with non-local conditions in Banach space, British Journal Mathematics Computer Science, 4 (2014) (6), 73-83.

[12] Y. Liu, B. Ahmad, A study of impulsive multiterm fractional differential equations with single and multiple base points and applications, The Scient. World J., 2014 (2014), Art. ID- 194346, pp-28.

[13] K. S. Miller, B. Ross, An Introduction to the Fractional Calculus and Fractional Differential Equation, John Wiley and Sons, Inc., New York, 1993.

[14] S. G. Samko, A. A. Kilbas, O. I. Marichev, Fractional Integrals and Derivatives: Theory and Applications, Gordon and Breach Science Publisher, Yverdon, 1993. 
[15] A. A. Kilbas, H. M. Srivastava, J. J. Trujillo, Theory and Applications of Fractional Differential Equations, Elsevier, Amsterdam, 2006.

[16] I. Podlubny, Fractional Differential Equations, Mathe. Sci. Eng., vol. 198, Academic Press, San Diego 1999.

[17] X. Liu, M. Jia, B. Wu, Existence and uniqueness of solution for fractional differential equations with integral boundary conditions. Elect. J. Qualit. Theory Diff. Equ. 2009 (2009) 69, pp-10 (2009).

[18] A. Ahmad, A. Alsaedi, B. S. Alghamdi, Analytic approximation of solutions of the forced Duffing equation with integral boundary conditions, Nonlinear Analysis: Real World Applications, 9 (2008), 1727-1740.

[19] B. Ahmad, J. J. Nieto, Existence results for nonlinear boundary value problems of fractional integrodifferential equations with integral boundary conditions, Boundary Val. Prob., 2009 (2009), Article ID-708576, pp-11.

[20] M. Muslim, D. Bahuguna, Existence of solutions to neutral differential equations with deviated arguments, Elect. J. Qualit. Theory Diff. Equ., (2008) 27, 1-12.

[21] R. Haloi, D. N. Pandey, D. Bahuguna, Existence of solutions to a non-autonomous abstract neutral differential equation with deviated argument, J. Nonlinear Evol. Equ. Appl., (2011) 5, 75-90.

[22] L. E. El'sgol'ts, S. B. Norkin, Introduction to the Theory of Differential Equations with Deviating Arguments, Academic Press 1973.

[23] Z.-W. Lv, J.-J. Xiao, Solutions to fractional differential equation with nonlocal initial conditions in Banach space, Adv. Diff. Equ., 2010 (2010), ID 340349, pp-10.

[24] C. G. Gal, Nonlinear abstract differential equations with deviated argument, J. Math. Anal. Appl., 333 (2007), 971-983.

[25] X. He, J. Xie, G. Chen, J. Shen, Integral BVPs for a class of first order impulsive functional differential equations, Int. J. Diff. Equ., 2010 (2010), Art. ID 908960, pp-11.

[26] G. Song, Y. Zhao, X. Sun, Integral boundary value problems for first order impulsive integrodifferential equations of mixed type, J. Comp. Appli. Math., 235 (2011), 2928-2935.

[27] Y. K. Chang, A. Anguraj, P. Karthikeyan, Existence results for initial value problems with integral conditions for impulsive fractional differential equations, J. Fract. Cal. Appl., 2 (2011), $1-10$. 